\title{
MULTIVARIATE STOCHASTIC DOWNSCALING MODELS FOR GENERATING PRECIPITATION AND TEMPERATURE SCENARIOS OF CLIMATE CHANGE BASED ON ATMOSPHERIC CIRCULATION
}

\author{
D. PANAGOULIA ${ }^{1, *}$ \\ A. BARDOSSY' \\ G. LOURMAS ${ }^{1}$
}

\author{
${ }^{1}$ National Technical University of Athens \\ School of Civil Engineering, Dept. of Water Resources \\ \& Environmental Engineering \\ 5 Heroon Polytechniou, 15780 Athens, Greece \\ ${ }^{2}$ Institute of Hydraulic Engineering, University of Stuttgart \\ Pfaffenwaldring 61, 70550, Stuttgart, Germany
}

Received: $15 / 11 / 07$

Accepted: 14/12/07 *to whom all correspondence should be addressed: e-mail: dpanag@hydro.civil.ntua.gr

\begin{abstract}
The spatial resolution of General Circulation Models (GCMs) is too coarse to represent regional climate changes at the scales required for environmental impact assessment. Therefore, downscaling of precipitation and temperature has to be carried out from the GCM grids to smaller scales of a few square kilometres. Daily precipitation and temperature are modelled as stochastic processes coupled to atmospheric circulation. Precipitation is linked to circulation patterns (CPs) using conditional model parameters. Temperature is modelled using a simple autoregressive model conditioned on atmospheric circulation and local daily precipitation. The models use an automated objective classification of daily atmospheric circulation patterns based on optimized fuzzy rules. Both temperature and precipitation are downscaled to several locations taking into account the CP dependent spatial correlation. The models were applied to the Mesochora medium-sized mountainous catchment in Central Greece for validation using observed precipitation and temperature and observed classified geo-potential heights (at $700 \mathrm{hPa}$ ). GCM scenarios of the ECHAM4 model for $1 \mathrm{xCO}_{2}$ and $2 \mathrm{xCO}_{2}$ cases were used to make climate change predictions (by using classified GCM geopotential heights). Simulated values agree fairly well with historical data. Most of the GCM results (incl. mean daily values, renewal process probabilities, spell lengths) under the $2 \mathrm{xCO}_{2}$ case reflect a somewhat wetter and a more variable precipitation regime over the Mesochora catchment with significantly increased daily mean temperatures.
\end{abstract}

KEYWORDS: atmospheric circulation, automated objective classification, autoregressive model, fuzzy rules, global warming, multivariate stochastic downscaling, precipitation, temperature.

\section{INTRODUCTION}

The interactions between hydrological cycle, biosphere, and climate system involve a large number of processes that operate over a continuous range of spatial and temporal scales (see for example Dooge, 1992; BAHC, 1993; Gash et al., 1996, Panagoulia and Dimou, 1997a; 1997b). The usefulness of the present general circulation models (GCMs) and higherresolution limited area models (LAMs) of the climate system is restricted due to their coarse spatial resolution. These last models are frequently associated with river basin or catchment scale processes, such as convective precipitation, vapour transfer, and other surface energy fluxes, which cannot be explicitly analysed at the spatial scales of GCMs (Wilby and Dettinger, 2000). In other words, there is a scale mismatch between land-surface parameterisations and large-scale atmospheric circulation which leads to major problems 
particularly under global warming scenarios because their inherent uncertainty is introduced to the most uncertain components of climate models, namely, water vapour and cloud feedback effects.

Statistical "downscaling" methodologies have subsequently emerged to satisfy the need for interpolation of regional-scale atmospheric predictor variables (e.g., area averages precipitation, temperature, geo-potential heights, vorticity, and teleconnection indices) to point-scale meteorological series (Wilby et al., 1998a; Wilby and Wigley, 2000). Fundamental to these methodologies is the establishment of stable empirical relationships between atmospheric processes occurring at disparate temporal and/or spatial scales.

In particular, mesoscale weather patterns have been used to model a variety of meteorological variables such as precipitation occurrence (Hughes and Guttorp, 1994), space-time daily rainfall patterns (Bárdossy and Plate, 1992), daily mean precipitation and temperature (Matyasovszky et al., 1993; 1994), monthly mean temperature and precipitation (Wigley et al., 1990), extreme precipitation events and drought conditions (Hay et al., 1991), low frequency precipitation events (Wilby, 1998), episodic soil loss from farmland (FavisMortlock et al., 1991), and sea level anomalies (Maochang et al., 1995; Heyen et al., 1996). The theory, limitations, and practice of downscaling methods for a wide range of predictors are extensively described in the literature (e.g. Giorgi and Mearns, 1991; Laevesley, 1984; Wilby and Wigley, 1997; 2000; Wilby et al., 1998b).

The aim of this paper is to explore the downscaled daily precipitation and temperature under global warming scenarios. We compare the precipitation and temperature values between "observed" and "present day" (1961-2000) simulations for $1 \mathrm{xCO}_{2}$ as a means of verifying the latter, and then the "present day" and "perturbed" (2061-2100) simulations for $2 \mathrm{xCO}_{2}$ in order to assess the possible changes due to global warming. The daily precipitation was modelled as a multivariate stochastic process coupled with atmospheric circulation (Shehlik and Bárdossy, 2002; Panagoulia et al., 2006b). The daily temperature was modelled as a simple autoregressive process conditioned on atmospheric circulation and local daily precipitation (Bárdossy and Mierlo, 2000). An automated objective classification method of daily circulation patterns (CPs) based on optimized fuzzy rules (Bárdossy et al., 2002; Panagoulia et al., 2006a) was undertaken. This type of classification defines CPs that can explain the variability of precipitation and temperature in a locally specific functional form thus ensuring the dependence between large-scale atmospheric circulation and surface climate that is necessary for precipitation and temperature downscaling. The concept of fuzzy sets has the advantage for dealing with imprecision and ambiguity (Makropoulos and Butler, 2004).

The downscaling and linking of precipitation and temperature to observed CPs as well as to ECHAM4 GCM-generated CPs for "present day" $\left(1 \mathrm{xCO}_{2}\right)$ and "perturbed" $\left(2 \mathrm{xCO}_{2}\right)$ climate scenarios was performed over the medium-sized mountainous catchment of Mesochora in Central Greece. The sector $10^{\circ}-40^{\circ} \mathrm{W}$ and $35^{\circ}-65^{\circ} \mathrm{N}$ over the $700 \mathrm{hPa}$ geo-potential height for the two $\mathrm{CO}_{2}$ cases was used. Various statistical descriptors, graphical displays and significance tests were used to quantify and demonstrate the changes in precipitation and temperature simulations between observed, "present day" $\left(1 \mathrm{xCO}_{2}\right)$ and "perturbed" $\left(2 \mathrm{xCO}_{2}\right)$ scenarios.

\section{METHODOLOGY}

The modelling of precipitation and temperature downscaling from a GCM grid to a regional resolution of a few square kilometers includes three parts. The first part constitutes the classification method of daily circulation patterns for present and future climates (in this case: precipitation and temperature). The second and third part reflects the precipitation and temperature downscaling model correspondingly, both linked to the classified circulation patterns. A brief description of method and model operation of the three parts is presented below.

\subsection{CLASSIFICATION METHOD}

The classification method selected was the fuzzy-rules based approach combined with a simulated annealing algorithm (Bárdossy et al., 2002; Panagoulia et al., 2006a). It consists of 
three steps: (1) data transformation; (2) definition of the fuzzy rules, and (3) classification of observed data. The classification is carried out using normalized geo-potential heights $g(i, t)$ of daily geo-potential height data (where $i$ denotes the grid-point and $t$ denotes the day). The purpose of the classification is to identify unusually wet or dry, warm or cold local conditions from the large scale pressure distribution. The geo-potential height data used are obtained from the NMC grid-point data set for different windows over Europe with a grid resolution of $5^{\circ} \times 5^{\circ}$.

Each CP is described with a fuzzy rule $k$ represented by a vector $v(k)=\left(v(1)^{(k)} \ldots v(n)^{(k)}\right)$, where $n$ is the number of grid-points for which the air-geo-potential height data are available. The $v(i)^{(k)}$ are the indices of the membership function corresponding to the selected locations. Five possible classes of membership functions $v$ were considered. These are "very low", "medium low", "medium high", "very high", and the case of "no influence" on the CP. The algorithms of membership function, membership grades and degree of fulfillment DOF of the rule are explicitly described in Bárdossy et al. (2002).

In order to find the appropriate rules for the description of local precipitation and temperature three types of objective functions were used to measure the classification performance:

- The first deals with the precipitation probability on a given day

- The second with precipitation amount in order both to define the precipitation variability (very wet and very dry conditions).

- The third refers to temperature geo-potential heights (separate classification) and is considered to define very cold and some very warm CPs within one classification.

The quality of the classification based on temperature is determined by using the index $I_{T}$ that denotes the average daily absolute difference between CP-conditioned temperature cycles and the unconditioned cycle for all CPs for the same station. Higher values of $\mathrm{I}_{\mathrm{T}}$ indicate a better classification. The algorithms of the objective functions and the index $I_{T}$ is fully described in Bárdossy et al. (2002) and Panagoulia et al. (2006a).

\subsection{PRECIPITATION DOWNSCALING MODEL}

The main difficulties in mathematical modelling of daily precipitation are: space-time intermittence, the occurrence probability of dry days, the rainfall amounts on wet days, as well as the clustering of wet and dry day occurrence that has great impacts on the CPs persistence. Taking into account these problems, a modified version of the space- time model proposed in Bárdossy and Plate (1992) which was developed in Shehlik and Bárdossy (2002) was adopted in this work.

In this respect, let $\mathbf{A}=\left\{\alpha_{1}, \ldots, \alpha_{n}\right\}$ be a set of possible atmospheric circulation patterns and $\tilde{A}_{t}$ be the random variable describing the actual atmospheric circulation taking its values from $A$. Also, let the daily precipitation amount at time $t$ and point $u$ in the region $U$ be modelled as the random function $Z(t, u)$. The distribution of rainfall amounts at a selected location is heavily skewed. In order to relate it to a simple normally distributed random function $W(t, u)$ (for any locations $u_{1}, \ldots u_{n}$ the vector $\left(W\left(t, u_{1}\right), \ldots, W\left(t, u_{n}\right)\right)$ is a multivariate normal random vector) the following power transformation relationship is introduced.

$Z(t, u)= \begin{cases}0 & \text { if } W(t, u) \leq 0 \\ W^{\beta}(t, u) & \text { if } W(t, u)>0\end{cases}$

Where, $\beta$ is an appropriate positive exponent. In this way the mixed (discrete-continuous) distribution of $Z(t, u)$ is related to a normal distribution. As the process $Z(t, u)$ depends on the atmospheric circulation pattern, this can be applied to $W(t, u)$. The reason for this transformation is that multivariate processes can be modelled much easier if the process is normally distributed. The intermittence can also be handled this way, as the negative values of $W$ are declared as dry days and dry locations. The exponent $\beta$ is needed because the distribution of precipitation amounts is generally considered more skewed than the truncated normal distribution. Eq. (1) establishes the link between $W(t)$ and rainfall $Z(t)$ as a multi-site 
process. The parameters of $\mathrm{W}(t)$ depend on the CP and the day of the year $t$. The annual cycle of the parameters is described by using Fourier series.

\subsection{TEMPERATURE DOWNSCALING MODEL}

The space-time variability of daily mean temperature can be described by the topography, the clear annual cycle, and the average elevation of a geo-potential level $H_{p}$ (such as 700 or 500 $\mathrm{hPa}$ ). Even, the temperature depends on the previous day's temperature and the $\mathrm{CP}$, and is also connected to the precipitation of the same day (Bárdossy and Mierlo, 2000).

$T(u, t)=F\left(u, H_{p}(t), \tilde{A}_{t}, T(u, t-1), Z(u, t)\right)$

The link between precipitation and temperature is established using the following indicator:

$\mathrm{I}_{\mathrm{z}}(\mathrm{t})= \begin{cases}1 & \text { if } \frac{1}{|G|} \int_{G} Z(t, u) d u \geq z_{0} \\ 0 & \text { else }\end{cases}$

The indicator depends on the areal precipitation, which is estimated from the observation points by ordinary kriging using the spatial correlation function of precipitation. Thus the kriging weights $\lambda_{i}$ do not depend on the time t.

$\frac{1}{|G|} \int_{G} Z(t, u) d u=\sum_{j=1}^{n} \lambda_{i} Z\left(u_{i}, t\right)$

Using the notation $\mathbf{T}(t)=\left(\mathrm{T}\left(u_{1}, \mathrm{t}\right), \ldots,\left(\mathrm{T}\left(u_{\mathrm{m}}, \mathrm{t}\right)\right), \mathbf{c}(I)=\left(\mathrm{c}_{1}(\mathrm{I}), \ldots,\left(\mathrm{c}_{\mathrm{m}}(\mathrm{I})\right)\right.\right.$ and $\mathbf{d}(\mathrm{I})=\left(\mathrm{d}_{1}(\mathrm{I}), \ldots,\left(\mathrm{d}_{\mathrm{m}}(\mathrm{I})\right)\right.$, the temperature model is developed. In this respect, a general relationship is assumed between the elevation and the pressure surface with residuals depending on the circulation pattern and the annual cycle.

$\mathrm{E}[\mathrm{T}(\mathrm{t})]=\mathbf{c}\left(\mathrm{I}_{\mathrm{Z}}(\mathrm{t})\right) \mathrm{H}_{\mathrm{p}}(\mathrm{t})+\mathbf{d}_{\mathrm{i}}\left(\mathrm{I}_{\mathrm{Z}}(\mathrm{t})\right)+\mathbf{R}_{\mathrm{i}}(\mathrm{t})$

Where $\mathbf{R}_{\mathrm{i}}(\mathrm{t})$ is the residual depending on the $\mathrm{i}^{\text {th }} \mathrm{CP}$ and the time of year $t$, and $\mathbf{c}(I)$ and $\mathbf{d}(\mathrm{I})$ the vectors of the coefficient used to describe this relationship. The components $R_{i}(u, t)$ of this function are expressed as Fourier series:

$$
R_{i}(u, t)=\sum_{k=0}^{K}\left(a_{k}\left(R_{i}, u\right) \sin (k w t)+b_{k}\left(R_{i}, u\right) \cos (k w t)\right)
$$

In order to obtain a model producing natural variability a first order auto-regressive $A R(1)$ type process is used:

$\mathbf{T}(\mathrm{t})=\mathbf{c}\left(\mathrm{I}_{\mathrm{z}}(\mathrm{t})\right) \mathrm{H}_{\mathrm{p}}(\mathrm{t})+\mathbf{d}\left(\mathrm{I}_{\mathrm{z}}(\mathrm{t})\right)+\mathbf{R}_{\mathrm{i}}(\mathrm{t})+\mathrm{P}_{\mathrm{i}}\left\{\mathrm{T}(\mathrm{t}-1)-\left[\mathrm{c}\left(\mathrm{I}_{\mathrm{z}}(\mathrm{t}-1)\right) \mathrm{H}_{\mathrm{p}}(\mathrm{t}-1)+\mathrm{d}\left(\mathrm{I}_{\mathrm{z}}(\mathrm{t}-1)+\mathbf{R}_{\mathrm{i}}(\mathrm{t}-1)\right]\right\}+\mathrm{S}_{\mathrm{i}} \Psi(\mathrm{t})\right.$

with $P_{i}$ being the CP dependent $\mathrm{m} \times \mathrm{m}$ matrix of the autoregressive part of the process and $\Psi$ a random vector of independent normalized random variables.

\section{STUDY CATCHMENT AND OBSERVED DATA SETS}

The Mesochora catchment, which is drained by the upper Acheloos' river in central Greece, was selected for as a case study due to its importance in view of its partial diversion, at the outfall of the catchment, to allow for the irrigation of the arid Thessaly plain and boost hydropower generation in the surrounding region. The catchment with an area of about 633 $\mathrm{km}^{2}$ lies in the central mountain region of Greece (Figure 1) and extends nearly $32 \mathrm{~km}$ from north $\left(39^{\circ} 42^{\prime}\right)$ to south $\left(39^{\circ} 25^{\prime}\right)$ with an average width of about $20 \mathrm{~km}$. The mean elevation is $1.390 \mathrm{~m}$., while the elevation from the highest point to the catchment outlet ranges from 2.200 $\mathrm{m}$ to $780 \mathrm{~m}$.

The climate of the area is dominated by cold and wet winters, as well as by warm and dry summers and the soils have been formed from decay of hard limestones and flysch (clayish, psammitic and mixed). The meteorological (precipitation and temperature) stations are installed within and around the catchment. Most of the stations are located at the lower half of the catchment over a range of elevations from 780 to $1160 \mathrm{~m}$. Daily precipitation was 
available at 12 stations for the period of 1967-1992, while daily minimum and maximum temperatures were collected from the totally installed 4 stations for the period of 1972-1992. The precipitation and temperature variability at the stations was determined by conditioning on CP types. It was found that the $700 \mathrm{hPa}$ data in the window $20^{\circ}-65^{\circ} \mathrm{N}$ and $20^{\circ} \mathrm{W}-50^{\circ} \mathrm{E}$ provided the best results, while the optimal number of CPs defined to 12 based on the automated objective optimization procedure for precipitation and temperature. As an example, for the Vakari station cited at the middle of the lower half of the catchment, the conditioned on observed CPs precipitation characteristics are presented in Table 1 for summer (MayOctober) and winter (November-April) seasons. The occurrence frequency of CPs is slightly different in each season and presents its higher values, in most cases, during the summer. The CP09 is the most frequent (37.20\% average over the year) and also driest contributing to precipitation by $4.0 \mathrm{~mm}$ daily amount and probability $22.50 \%$. At the same station, the CP01 is a typical wet CP (second in wet day amount-14.0 mm yearly) with high precipitation probability (65\% yearly) and low occurrence frequency (5.9\% yearly).

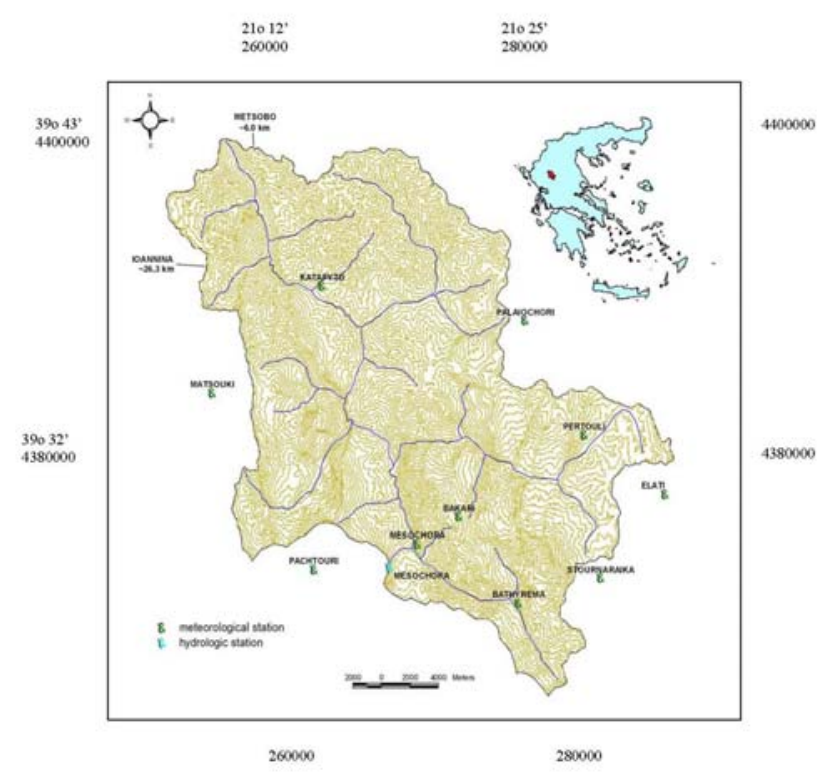

Figure 1. Elevation contour map of Mesochora catchment

The twelve temperature-optimized CPs were in general different from the twelve precipitationoptimized CPs. CP02 is the warmest CP producing a movement of warm air from the southwest direction over Greece. The coldest CP, CP10 $\left(I_{T}=2.40{ }^{\circ} \mathrm{C}\right)$, is characterized by a negative geo-potential height over the Central-East Europe (Panagoulia et al., 2006a). A spatial correlation function using time series cross correlations was assessed for interpolation of point precipitation data to a regular grid. Subsequently the data were integrated into 9 zones over the entire area. For this purpose external drift kriging was used. The zoning distribution of precipitation showed that the precipitation increases slightly with increasing elevation. For the temperature, a lapse rate, i.e. a rate of temperature decrease with elevation for daily data, was determined. Then, the temperature data were integrated into zones over the entire area. The zoning distribution of temperature showed that the temperature decreases progressively with increasing elevation.

\section{CALIBRATION WITH OBSERVED DATA SETS}

In the calibration procedure, the observed daily precipitation and temperature series for all the periods with available data were used to estimate coupling parameters, which describe the stochastic links between CPs and point measurements. Using these attained parameters the precipitation and temperature time series were simulated (generated). The stochastic models simulated the point time series very well. As an example, for the Vakari station, observed $\left(4.34 \mathrm{~mm} \mathrm{~d}^{-1}\right)$ and simulated $\left(3.95 \mathrm{~mm} \mathrm{~d}^{-1}\right)$ average daily mean precipitation in a yearly basis agree well enough. Standard deviations of $3.40 \mathrm{~mm} \mathrm{~d}^{-1}$ (observed) and $2.27 \mathrm{~mm} \mathrm{~d}{ }^{-1}$ (simulated) also show a good agreement. Similar or slightly better values are calculated for 
the other stations. Average deviation between observed and simulated temperature on mean daily basis is about $0.20^{\circ} \mathrm{C}$ for all 4 stations. For CP02 and CP 10 cases the average deviation between observed and simulated temperature on a daily basis is about $0.12^{\circ} \mathrm{C}$ for $\mathrm{CP} 02$ and $0.10^{\circ} \mathrm{C}$ for $\mathrm{CP} 10$ at all 4 stations.

Table 1. Precipitation characteristics conditioned on CP's for Vakari station

\begin{tabular}{|c|c|c|c|c|c|c|c|c|c|c|c|c|c|}
\hline CP: & & 1 & 2 & 3 & 4 & 5 & 6 & 7 & 8 & 9 & 10 & 11 & 12 \\
\hline \multicolumn{14}{|c|}{ Precipitation Probability (\%) } \\
\hline \multirow[t]{2}{*}{ Vakari } & summer & 47.50 & 37.25 & 33.53 & 25.96 & 45.68 & 47.73 & 21.59 & 31.03 & 18.45 & 55.47 & 12.70 & 28.00 \\
\hline & winter & 81.82 & 60.67 & 65.71 & 67.14 & 59.49 & 56.00 & 60.94 & 60.00 & 26.45 & 94.94 & 57.58 & 49.28 \\
\hline \multicolumn{14}{|c|}{ Mean wet day amount (mm) } \\
\hline \multirow[t]{2}{*}{ Vakari } & summer & 8.82 & 8.54 & 12.88 & 5.99 & 8.82 & 6.24 & 3.55 & 8.29 & 4.87 & 12.26 & 6.20 & 4.80 \\
\hline & winter & 19.09 & 6.15 & 15.02 & 10.94 & 8.26 & 8.45 & 10.43 & 10.77 & 3.21 & 24.68 & 12.90 & 9.43 \\
\hline \multicolumn{14}{|c|}{ Standard deviation of wet-day amount (mm) } \\
\hline \multirow[t]{2}{*}{ Vakari } & summer & 8.78 & 12.11 & 15.78 & 9.11 & 13.02 & 12.19 & 4.09 & 13.60 & 8.89 & 16.01 & 9.09 & 7.10 \\
\hline & winter & 18.83 & 9.57 & 17.85 & 14.23 & 10.83 & 10.45 & 14.68 & 12.60 & 5.73 & 24.25 & 14.88 & 16.52 \\
\hline \multicolumn{14}{|c|}{ CP occurrence frequency (\%) } \\
\hline \multirow[t]{2}{*}{ Vakari } & summer & 3.95 & 5.04 & 8.55 & 5.14 & 4.00 & 2.17 & 4.35 & 4.30 & 38.83 & 6.32 & 9.34 & 3.71 \\
\hline & winter & 7.75 & 8.95 & 5.28 & 7.04 & 3.97 & 2.52 & 3.22 & 3.27 & 35.56 & 8.95 & 6.64 & 3.47 \\
\hline \multicolumn{14}{|c|}{ CP wetness index (precipitation contribution/occurrence frequency) } \\
\hline \multirow[t]{2}{*}{ Vakari } & summer & 1.94 & 1.47 & 2.00 & 0.72 & 1.86 & 1.38 & 0.35 & 1.19 & 0.41 & 3.14 & 0.36 & 0.62 \\
\hline & winter & 2.39 & 0.57 & 1.51 & 1.12 & 0.75 & 0.72 & 0.97 & 0.99 & 0.13 & 3.58 & 1.14 & 0.71 \\
\hline
\end{tabular}

In general, the average temperature deviations for all CP types are minimal. Variability and average behaviour of precipitation and temperature was well described via the annual cycle and spatial structure. As an example, Figure 2 presents a good agreement between observed and simulated long-term daily precipitation in the dry periods of spring and fall seasons at the Vakari station over the period 1967-1992. A less accurate agreement was obtained for annual maxima between modelled and observed profiles. As examples of temperature, Figures 3 and 4 reflect the mean annual cycle of observed and simulated temperature at all 4 stations for CP02 and CP10 respectively over the period 1980-1989. Figures 3 and 4 reflect a very good fitting between simulated and measured daily temperature during the year for the two CP types. The agreement of profiles between simulated and observed annual maxima is also fully satisfactory.

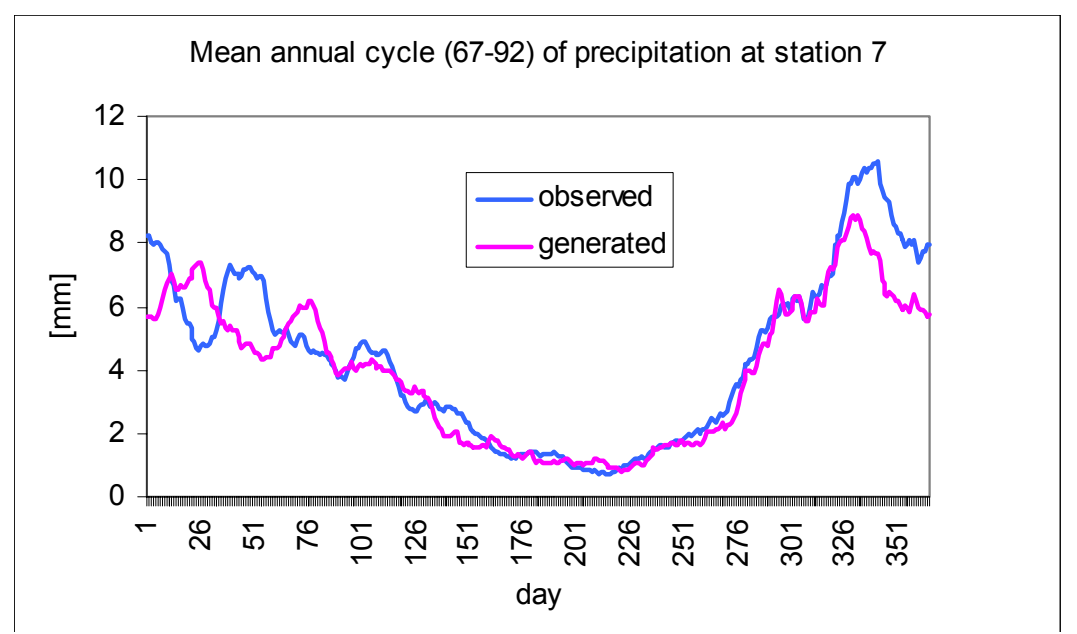

Figure 2. Long-term mean daily precipitation at Vakari station 


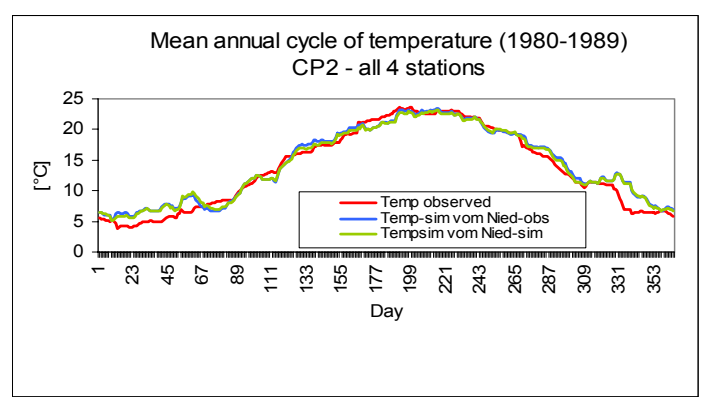

Figure 3. Mean annual cycle of temperature at all 4 stations for CP2: observed and simulated by the temperature model for the period 1980-1989

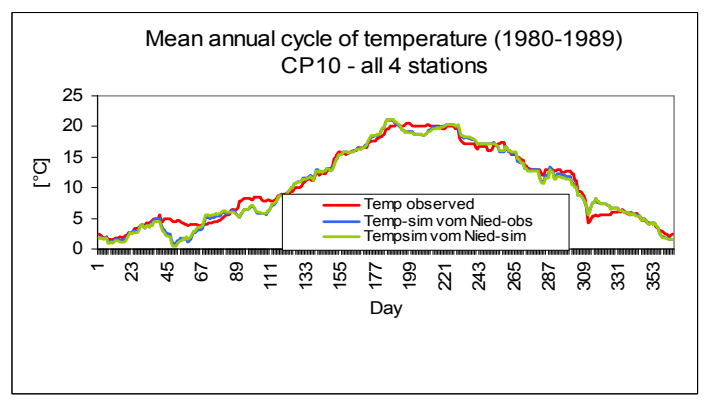

Figure 4. Mean annual cycle of temperature at all 4 stations for CP10: observed and simulated by the temperature model for the period 1980-1989

\section{DOWNSCALED PRECIPITATION AND TEMPERATURE UNDER CLIMATE CHANGE}

Beyond the downscaling of observed precipitation and temperature (from 1972 to 1992) over the Mesochora catchment, downscaling was also carried out for ECHAM4 GCM-generated circulation patterns. The analysis was based on daily values at the aforesaid sector $20^{\circ} \mathrm{W}$ $50^{\circ} \mathrm{E}$ and $20^{\circ}-65^{\circ} \mathrm{N}$ over the $700 \mathrm{hPa}$ geo-potential level for $1 \mathrm{xCO}_{2}$ and $2 \mathrm{xCO}_{2}$ scenarios for the corresponding periods 1961-2000 and 2061-2100 (Panagoulia et al., 2006a).

Applying the classification method described for the observed data (precipitation and temperature) the geo-potential heights of both climate scenarios were classified. With the attained parameters of the stochastic precipitation model for the observed data and forcing the model by the two cases of classified GCM-CPs, precipitation time series were generated responding to climate scenarios. Simulated precipitation time series and GCM-CPs time series were jointly used to generate temperature time series reflecting the two climate cases.

The annual cycle (average daily values over the year) of precipitation over the catchment area for the three climate cases is presented in Figure 5. There was a better agreement between observed and $1 \mathrm{xCO}_{2}$ simulated precipitation in dry months (June, July, August) than in wet ones (January to March), while the $2 \mathrm{xCO}_{2}$ case boosted significantly the daily precipitation in the wet months (from January to March, and from October to November). The probability distribution function of daily precipitation amount for the three climate scenarios can be seen in Figure 6 . The $2 \mathrm{xCO}_{2}$ case produced a slight increase in precipitation amount compared both to observed and $1 \mathrm{xCO}_{2}$ cases. The significance test of normal limiting distribution with zero expected value and unit variance at $95.5 \%$ level for daily mean wet precipitation amount between observed, $1 \mathrm{xCO}_{2}$ and $2 \mathrm{xCO}_{2}$ scenarios validated the close matching of observed and $1 \mathrm{xCO}_{2}$ downscaled precipitation and the statistically significant difference between observed and $2 \mathrm{xCO}_{2}$ downscaled precipitation as well as the difference between $1 \mathrm{xCO}_{2}$ and $2 \mathrm{xCO}_{2}$ downscaled precipitation.

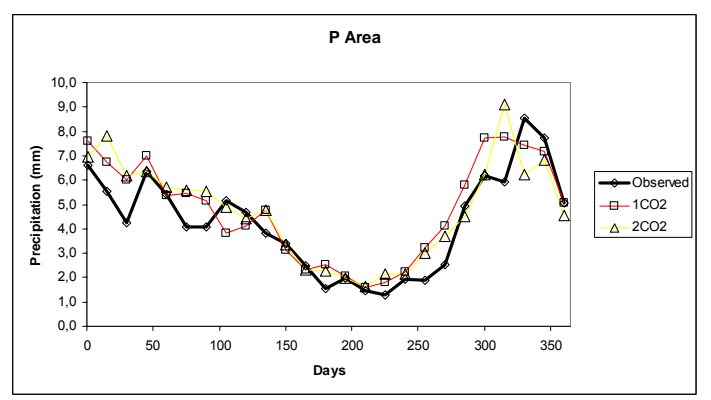

Figure 5. Average daily precipitation for observed (1972-1992) and simulated by the model with $1 \times \mathrm{xO}_{2}(1961-2000)$ and $2 \mathrm{xCO}_{2}$ (2061-2100) scenarios at the Mesochora catchment

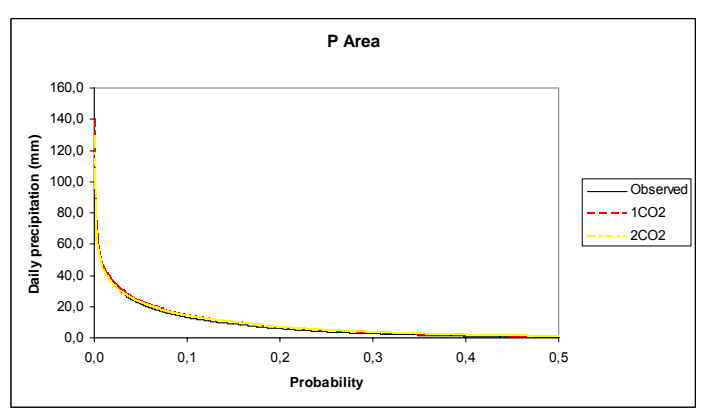

Figure 6. Probability distribution function of daily precipitation amount for observed (1972-1992) and simulated by the model with $1 \times \mathrm{XO}_{2}(1961-2000)$ and $2 \mathrm{xCO}_{2}(2061-2100)$ scenarios at the Mesochora catchment 
Concerning the daily variability of precipitation over the catchment area, the compared diagnostic statistics under the three climate scenarios (Table 2) revealed for the $2 \mathrm{xCO}_{2}$ case that: (a) there was a general decrease in the values of the first and second moments and dryto-dry day renewal process probabilities, (b) the values of wet-to-wet/dry day renewal process probabilities remained substantially unchanged and (c) the values of dry spell statistics decreased, while the values of wet spell statistics did not changed significantly. The examined statistics are presented for the 9 zones and the entire area of the catchment in Panagoulia et al., 2006b.

The averaged daily values of temperature in the year (annual cycle) over the 1972-1992 period (Figure 7 ) presented a relatively good fit between historical and $1 \mathrm{xCO}_{2}$ case for the examined catchment area. The $2 \mathrm{xCO}_{2}$ case reflected a temperature increase of $3{ }^{\circ} \mathrm{C}$ in all averaged daily values compared to the observed ones. Figure 8 shows the probability distribution function of mean daily temperature of the catchment area using the observed and the two $\mathrm{CO}_{2}$ climate scenarios. The probability of daily temperature occurrence appeared to be almost identical between observed and $1 \mathrm{xCO}_{2}$ case. The warmest climate scenario $\left(2 \times \mathrm{CO}_{2}\right.$ case $)$ increased the frequency of daily temperature and boosted the temperature values by $4{ }^{\circ} \mathrm{C}$ to $5{ }^{\circ} \mathrm{C}$. The Wilcoxon Signed Rank significance test applied for five probability levels $(95.0 \%, 97.5 \%, 99.0 \%, 99.5 \%, 99.9 \%)$ revealed a significant increase in daily temperature between observed and $2 \mathrm{xCO}_{2}$ case, as well as between $1 \mathrm{xCO}_{2}$ and $2 \mathrm{xCO}_{2}$ cases.

Table 2. Results in downscaled precipitation diagnostics between observed (1972-1992), $1 \mathrm{xCO}_{2}(1961-2000)$ and $2 \mathrm{xCO}_{2}(2061-2100)$ climate scenarios

\begin{tabular}{|c|c|c|c|c|c|c|c|}
\hline \multirow[b]{2}{*}{ Diagnostics } & \multicolumn{3}{|c|}{ P Area } & \multirow[b]{2}{*}{ Diagnostics } & \multicolumn{3}{|c|}{ P Area } \\
\hline & Obs. & $1 \mathrm{CO}_{2}$ & $2 \mathrm{CO}_{2}$ & & Obs. & $1 \mathrm{CO}_{2}$ & $2 \mathrm{CO}_{2}$ \\
\hline Mean wet-day amount: & 7.09 & 6.79 & 6.36 & $\Pi_{w}:$ & 0.60 & 0.69 & 0.73 \\
\hline $\begin{array}{l}\text { Standard deviation of } \\
\text { wet-day amount: }\end{array}$ & 11.25 & 11.09 & 10.38 & $\mathrm{~L}_{d}:$ & 3.57 & 2.35 & 1.97 \\
\hline Median wet-day amount: & 2.99 & 2.79 & 2.61 & $\mathrm{~L}_{\mathrm{w}}:$ & 5.14 & 4.82 & 5.12 \\
\hline $\begin{array}{l}\text { 95th percentile of } \\
\text { wet-day amount: }\end{array}$ & 30.06 & 29.48 & 27.57 & Standard deviation of $L_{d}$ : & 3.63 & 1.95 & 1.51 \\
\hline $\mathrm{P}_{00}:$ & 0.72 & 0.54 & 0.49 & Standard deviation of $L_{w}$ : & 6.17 & 5.44 & 6.07 \\
\hline$P_{11}:$ & 0.81 & 0.79 & 0.81 & 90th percentile of $L_{d}$ : & 8 & 5 & 4 \\
\hline $\mathrm{P}_{01}$ : & 0.28 & 0.46 & 0.51 & 90th percentile of $L_{w}$ : & 11 & 11 & 12.5 \\
\hline$P_{10}:$ & 0.19 & 0.21 & 0.19 & $\begin{array}{r}\text { Standard deviation of } \\
\text { monthly precipitation } \\
\text { total: }\end{array}$ & 91.59 & 97.99 & 90.71 \\
\hline
\end{tabular}

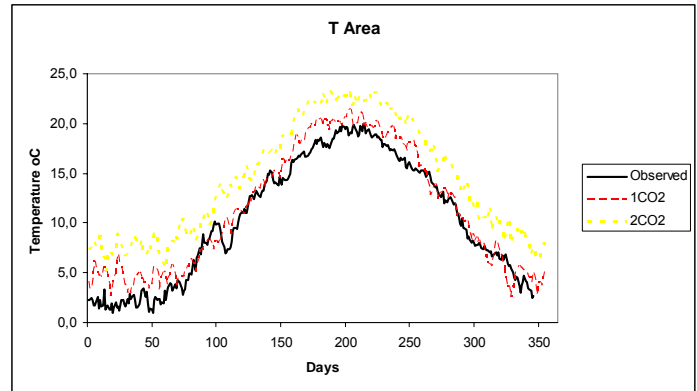

Figure 7. Average mean daily temperature for observed (1972-1992) and simulated by the model with $1 \mathrm{xCO}_{2}(1961-2000)$ and $2 \mathrm{xCO}_{2}$ (2061-2100) scenarios at the Mesochora catchment

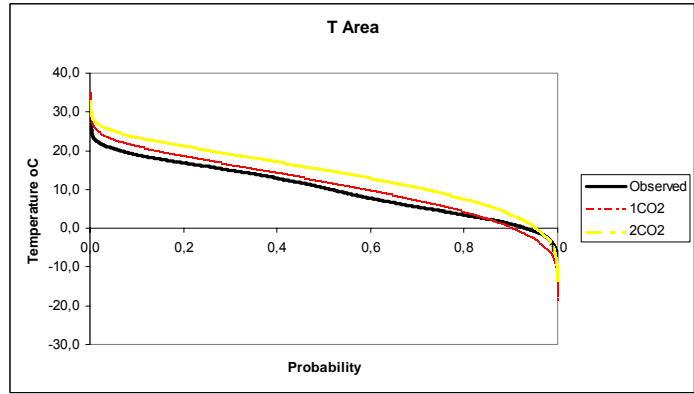

Figure 8. Probability distribution function of daily temperature for observed (1972-1992) and simulated by the model with $1 \mathrm{xCO}_{2}$ (1961-2000) and $2 \times \mathrm{CO}_{2}(2061-2100)$ scenarios at the Mesochora catchment 


\section{SUMMARY AND CONCLUSIONS}

A multivariate stochastic downscaling model (Stehlik and Bárdossy, 2002) coupled with atmospheric circulation was employed to generate daily precipitation series. The daily temperature series were simulated using a simple autoregressive model conditioned on atmospheric circulation and local daily precipitation. Both models used the fuzzy rule-based automated objective classification method in Bárdossy et al. (2002) to classify observed circulation patterns (CPs) and GCM-produced $\mathrm{CPs}$ for $1 \mathrm{xCO}_{2}$ and $2 \mathrm{xCO}_{2}$ climate scenarios. The objective classification method produced physically realistic circulation patterns at 700 $\mathrm{hPa}$ geo-potential level over the medium-sized mountainous Mesochora catchment in Central Greece with prevailing high and low geo-potential heights. This is in good agreement with the division of all the synoptic systems into cyclonic and anti-cyclonic (low and high geo-potential patterns) for Greece in Maheras et al. (2000) and Anagnostopoulou et al. (2004).

The comparison of downscaled daily precipitation and temperature series for identifying differences between observed, $1 \mathrm{xCO}_{2}$ and $2 \mathrm{xCO}_{2}$ climate scenarios revealed that the downscaled observed and GCM-"present day" precipitation and temperature are generally in a reasonable agreement. The GCM-"perturbed" for $2 \mathrm{xCO}_{2}$ climate scenario increased significantly the daily precipitation during the wet months and slightly the frequency of the daily precipitation occurrence. The diagnostic statistics also suggested a possible increase in the daily precipitation occurrence but with a decreasing precipitation amount and a sequence of less consecutive dry days. The GCM-"perturbed" for $2 \mathrm{xCO}_{2}$ climate scenario increased significantly the frequency of daily temperature occurrence as well as the mean daily temperature.

The work presented here, indicates the general character of precipitation and temperature changes that would occur in catchments with similar hydrological and meteorological features and presents a methodology to further investigate diversity using other GCM outputs.

\section{REFERRENCES}

1. Anagnostopoulou C., Flocas H., Maheras P., Patrikas I. (2004) Relationship between atmospheric circulation types over Greece and western-central Europe during the period 1958-97, Int.J. Climat., 24, 1745-1758.

2. BAHC Core Project Office (1993) Biospheric aspects of the hydrological cycle. Rep. 27. Institut fur Meteorologie: Berlin.

3. Bárdossy A. and Mierlo J.M.C. (2000) Regional precipitation and temperature scenarios for climate change, Hydrol. Sci. J., 45(4), 559-575.

4. Bárdossy A. and Plate E.J. (1992) Space-time model of daily rainfall using atmospheric circulation patterns, Wat. Resour. Res., 28(5), 1247-1259.

5. Bárdossy A., Stehlík J., Caspary H.J. (2002) Automated optimized fuzzy rule based curculation pattern classification for precipitation and temperature downscaling, Clim. Res., 22, 11-22.

6. Dooge J.C.I. (1992) Hydrologic Models and Climate Change, J. of Geophysical Research, 97(D3), 2677-2685

7. Favis-Mortlock D.T., Evans R., Boardman J., Harris T.M. (1991) Climate change, winter wheat yield and soil erosion on the English South Downs, Agri. Syst., 37, 415-433.

8. Gash J.H.C, Nobre C.A., Roberts J.M., Victoria R.L. (1996) Amazonian Deforestation and Climate. Jone Wiley \& Sons, Press by Institute of Hydrology: Printed in Great Britain.

9. Giorgi F. and Mearns L.O. (1991) Approaches to the simulation of regional climate change - A review, Rev. Geophys., 29, 191-216.

10. Hay L.E., McCabe G.J., Wolock D.M., Ayers M.A. (1991) Simulation of precipitation by weather type analysis, Water Resour. Res., 27, 493-501.

11. Heyen H., Zorita E., von Storch H. (1996) Statistical downscaling of monthly mean N. Atlantic air pressure to sea level anomalies in the Baltic Sea, Tellus Ser. A., 48,312-323.

12. Hughes J.P. and Guttorp P. (1994) A class of stochastic model for relating synoptic atmospheric patterns to regional hydrologic phenomena, Water Resour. Res., 30, 1535-1546.

13. Laevesley G.H. (1994) Modeling the effects of climate change on water resources - A review, Climate Change,28, 159-177. 
14. Maheras P., Patrikas I., Karacostas T., Anagnostopoulou C. (2000) Automatic classification of circulation patterns in Greece: methodology, description, frequency, variability and trend analysis, Theor. Appl. Climatol., 67, 205-223.

15. Makropoulos C. and Butler D. (2004) Spatial Decisions under Uncertainty: Fuzzy Inference in Urban Water Management, J. Hydroinformatics, 6(1), 3-18.

16. Maochang C., von Storch H., Zorita E. (1995) Coastal sea level and large-scale climate state. A downscaling exercise for the Japanese Islands, Tellus Ser. A., 47, 132-144.

17. Matyasovszky I., Bogardi I., Bárdossy A., Duckstein L. (1993) Space-time precipitation reflecting climate change, Hydrol. Sci. J., 38, 539-558.

18. Matyasovszky I., Bogardi I., Bárdossy A., Duckstein L. (1994) Local temperature estimation under climate change, Theor. Appl. Climatol., 50, 1-13.

19. Panagoulia D. and Dimou G. (1997a) Linking space-time scale in hydrological modelling with respect to global climate change. Part 1 . Models, model properties, and experimental design, J. Hydrol., 194, 15-37.

20. Panagoulia D. and Dimou G. (1997b) Linking space-time scale in hydrological modelling with respect to global climate change. Part 2. Hydrological response for alternative climates, J. Hydrol., 194, 38-63.

21. Panagoulia D., Bárdossy A., Lourmas G. (2006b) Diagnostic statistics of daily rainfall variability in an evolving climate, Advances in Geosciences, 7, 349-354.

22. Panagoulia D., Grammatikogiannis A., Bárdossy A. (2006a) An automated classification method of daily circulation patterns for surface climate data downscaling based on optimized fuzzy rules, Global Nest J., 8(3), 218-223.

23. Stehlik J. and Bárdossy A. (2002) Multivariate stochastic downscaling model for generating daily precipitation series based on atmospheric circulation, J. Hydrol., 256, 120-141.

24. Wigley M.L., Jones P.D., Briffa K.R., Smith G. (1990) Obtaining sub-grid scale information from coarse resolution general circulation model output, J. Geo-phys. Res., 95, 1943-1953.

25. Wilby R.L. and Dettinger M.D. (2000) Steamflow changes in the Sierra Nevada, California, simulated using a statistically downscaled general circulation model scenario of climate change. Linking Climate Change to Land Surface Change. McLaren SJ and Kniveton DR (eds.). Kluwer Academic Publishers: The Netherlands.

26. Wilby R.L. and Wigley T.M.L. (1997) Downscaling general circulation model output: a review of methods and limitations, Progress Phys. Geogr., 21, 530-548.

27. Wilby R.L and Wigley T.M.L. (2000) Precipitation predictors for downscaling observed and general circulation model relationships, Int. J. Climatol., 20, 641-881.

28. Wilby R.L, Hassan H., Hanaki K. (1998a) Statistical downscaling of hydrometeo-rological variables using general circulation model output, J. Hydrol., 205, 1-19.

29. Wilby R.L, Wigley M.L., Conway D., Jones P.D., Hewitson B.C., Main J., Wilks D.S. (1998b) Statistical downscaling of general circulation model output: a comparison of methods, Water Resour. Res., 34(11), 2995-3008.

30. Wilby RL. (1998) Modelling low frequency rainfall events using airflow indices, weather patterns and frontal frequencies, J. Hydrol., 212-213, 380-392. 